\title{
Discouraging Academic Dishonesty in Online Courses
}

\section{JANICE M CONWAY-KLAASSEN, DEBORAH E KEIL}

ABSTRACT: With the development of distance education and blended course delivery formats, our faculty faced new issues related to academic integrity in online testing. Current students often differ in their understanding of what is appropriate academic behavior and what is considered cheating. Enhancing quiz formats and educating faculty and students about academic integrity policies has minimized the situation in our program.

ABBREVIATIONS USED: CLS-Clinical Laboratory Sciences, IP-Internet Protocol, OIT-Office of Information Technology, OSC-Office of Student Conduct

KEY WORDS: Online testing, cheating, distance education, Web Campus, academic integrity

Clin Lab Sci 2010;23(4)194

Janice M. Conway-Klaassen, PhD, MT(ASCP)SM, University of Minnesota, Minneapolis, $M N$.

Deborah E. Keil, PhD, MT(ASCP), DABT, University of Utah, Salt Lake City. UT

Address for correspondence: Janice M. Conway-Klaassen, PhD, MT(ASCP)SM, Director, Clinical Laboratory Science, Center for Allied Health Programs, Mayo Mail Code 711, 420 Delaware St. SE, Minneapolis, MN 55455, 612-626-9408, 612-625-5901 (FAX), jconwayk @umn.edu

CASE PRESENTATION: The online quiz and exam cheating situation in the CLS Program began to unfold when faculty noticed discrepancies between student high quiz scores and the students' inability to actually discuss subject content in class. These discrepancies were occurring in several CLS disciplines however faculty had not yet met to collectively discuss their individual observations.

About the same time and just prior to a major on-line exam in one subject, a student stepped forward and reported to the Program Director that they had firsthand knowledge of "collaborative cheating" by fellow students; this individual had been invited to participate several times. The student struggled for some time with the decision to report their fellow students. While not wanting to compromise personal friendships they realized the potential impact on the program and profession as well as their personal integrity and code of ethics. They felt they had worked very hard for their B grade and did not feel it was fair for these others to get A's for no effort. The likely impact on patient safety is what finally brought them forward. Shortly after that another student came forward with similar information.

Program faculty reviewed student tracking data from Web Campus and engaged campus Office of Information Technology (OIT) to assist in the evaluation and interpretation of student test taking "strategies." Both OIT and CLS program faculty were able to identify that the student group in question occupied the same computer lab location on the same days and times to take their online quizzes and exams. The exam online format developed by some of our faculty was not totally secure and lack of time restrictions actually facilitated a collaborative effort allowing students to reference and/or correct answers for test questions during the exam. Further study by program faculty found that student exam submissions from this group showed evidence of complicity based on a) sequence of questions submitted and b) disparity in time between when the question "displayed" and answer "saved" relative to the degree of difficulty. For example, a leukemia case study was opened and answered in seven 


\section{CLINICAL PRACTICE}

seconds by four students when the average time for the rest of the class was 2-3 minutes. Also with each quiz one student in the group had an average score while the other students missed only one question each. They all missed the first question of each quiz but each student chose a different wrong choice. They apparently had done this to minimize suspicion and to make it appear as "random" errors. This pattern fit with the descriptions made by the students who reported the cheating. The first examinee (Student A) opened the test and printed the entire assessment. With the assistance of the group, Student A entered their answers and obtained their score showing their right/wrong answers. Then the other members would take the exam having the correct responses in hand but made sure they chose different answers on question one. Students rotated the role of first examinee so "the negative impact on the grade" was distributed within the group.

The university Office of Student Conduct (OSC) was consulted regarding what materials were needed for documentation and we discussed a remedial course action. Policies and Procedures for Student Conduct Code were disseminated to both students and faculty. During this period, it was also decided that the Program Director would council all CLS students about the definition of academic dishonesty and options for sanctions levied at the program and university level. The end goal was to create an environment in which the students would assume responsibility for their academic violations and self-report. The Associate Dean was also in attendance to make an impression concerning the gravity of the alleged violations.

As a consequence of the actions taken by program faculty, six students opted to write letters confessing/explaining the "how, when, where and in what courses" the academic violations occurred. We were not prepared for the depth and magnitude of the situation (number and frequency of incidents). After individual discussions with these students we were alarmed at the vast divergence between what students and faculty consider academic misconduct or cheating. Curiously all of these students felt that the "rules" were different for online quizzes compared to paper quizzes. Because we had not stated explicitly that these quizzes were to be taken alone and we had encouraged students to study together, they assumed that they could work together. One student who had a 4.0 GPA stated she thought she was "helping" the others by being involved in the group test taking process. None of them initially thought that this practice had compromised their learning and in fact they felt it strengthened their knowledge through group discussions. When confronted with the critical differences between their quiz grades and ability to discuss the course materials most of these students realized the folly of their rationale. After consultation with CLS program faculty, the OSC placed the following sanctions on the students involved in this situation. Two students were permanently removed from the CLS program and permanent notations were made on their transcripts regarding academic misconduct violations; one of these students was eventually suspended from the university. Two other students were suspended from the CLS program for one year and allowed to reapply with conduct sanctions on their transcript record while the final two received failing grades for the quizzes involved which greatly impacted their course grades. The different degrees of punitive action were based on the intensity, number and magnitude of the individual student's infractions, their involvement in previous integrity issues on campus, and their willingness to take responsibility for their behavior and undergo remediation training.

The atmosphere within all of the CLS courses was negatively influenced by this situation and the remaining students' morale suffered greatly. Faculty worked hard to reestablish a sense of normalcy in the classroom and to get students back on track. Information regarding academic integrity and definitions of academic misconduct was added to the CLS Student Manual. In addition, affective objectives were added to each course along with case study quiz questions to reinforce University and Program policies regarding academic misconduct. After a few weeks the students were back on track and actually expressed relief that we had dealt with the situation instead of letting it continue. 


\section{CLINICAL PRACTICE}

\section{BACKGROUND LITERATURE ON ACADEMIC DISHONESTY}

When it comes to cheating, today's youth have a very different definition of academic dishonesty than their parents or current authority figures. According to the Josephson Institute 2008 survey on Ethics in American Youth, $64 \%$ of high school students had cheated on a test in the past year; 38\% two or more times. ${ }^{1}$ Almost $60 \%$ of high school students felt that successful people did whatever was necessary to succeed even if it could be considered cheating; success at any cost. ${ }^{1}$ What was most interesting about this report is that over $90 \%$ of these same students perceived themselves as having high ethical standards. ${ }^{1}$ Similar statistics have been shown in studies amongst college-age students with up to $56 \%$ of graduate students cheating at least once in the past year. ${ }^{2,3,4,5}$

What seems to have changed over the years is an increase in planned cheating (deliberate strategy) instead of panic cheating (sneaking a look at neighbor's test paper). Test cheating and plagiarism are now a part of high school behavior and college campus culture. ${ }^{1,2,3,4}$ Campuses that had and enforced an Honor Code typically had fewer students reporting cheating activities $(24 \%) .^{3}$ These students thought that the higher probability of being caught or having significant consequences was a factor in their decision not to cheat.

Students' perception of what is dishonest is also a major component of their decision making strategy; the situation plays a significant role. When is it okay to cheat and when is it not okay? They felt that the situation dictated whether or not it was wrong - was someone else going to be directly hurt by their misconduct? ${ }^{3,4,6}$ They did not perceive themselves as being compromised by cheating. Many college students stated that cheating is "no big deal" that everyone does it at one time or another. ${ }^{1,6}$ Students were also less stringent on their definitions of plagiarism. Most agreed that turning in a paper someone else had written as their own was plagiarism, but consistently thought that copying individual sentences or short paragraphs was not plagiarism. ${ }^{4,6}$

Students also generally thought that campus policies were not enforced, out-dated and ill-defined leading to misconceptions on what to do or not to do and when. ${ }^{4,5}$ Those students who did not cheat felt that college policies and faculty failed to provide enough guidance, surveillance or enforcement leading to their frustration and eventually a feeling that cheating like everyone else was necessary to remain competitive. ${ }^{4,5,6,7}$ As long as faculty continued to ignore what was going on, students felt that cheating was in reality condoned.

One of the major findings in several studies is that students seem to have learned some of their dishonesty behavior from everyday adult examples. ${ }^{1,3,6}$ Today's students are constantly exposed to parents and other adults who misrepresent or omit critical facts in reports or interactions (e.g. tax returns, insurance or expense claims). With all these mixed messages it is difficult for most students to understand what is expected of them. We cannot assume they have the same interpretation that we have of what constitutes academic dishonesty. ${ }^{8}$

\section{DEVELOPING ACADEMIC INTEGRITY POLI- CIES}

How then do we as educators begin to address this culture within our courses and change students' perceptions of academic misconduct in our allied health professional programs? According to the current literature our role begins with frank discussions concerning the definitions (with specific examples) of what we consider academic misconduct and convey to them what we consider inappropriate in advance. ${ }^{5} \mathrm{We}$ must describe the consequences both from an academic position (grade sanctions) and from a position of medical ethics (impact on quality of practice and on patient care). We then implemented a segment in our new student orientation concerning academic integrity.

With assistance from the OSC we have updated our student manual to include discussions on academic integrity and definitions of cheating with examples from our program (Table 1). We have also implemented a segment in our new student orientation concerning academic integrity and a mandatory but not graded quiz asking students to evaluate whether the situation is a violation of our student conduct code and how they would manage the student involved. We then discussed their responses in groups. We had hoped that by pres- 


\section{CLINICAL PRACTICE}

Table 1. Examples of Academic Misconduct in Student Manual*

- Using the words or ideas of another, from the internet or any source, without proper citation of the sources, commonly called plagiarism.

- Turning in the same work in more than one class (or when repeating a class), unless permission is received in advance from the instructor.

- Falsifying information for inclusion in an assigned paper, project or exercise; including inventing or altering data from a laboratory or field project, or creating fictional citations for a paper.

- Attempting to influence or change any academic evaluation, assignment or academic records for reasons having no relevance to academic achievement. This includes, but is not limited to, bribery, threats and making unauthorized changes to any academic record.

- $\quad$ Falsifying or misrepresenting hours or activities in relationship to an internship, externship, field experience, clinical activity or similar activity.

- Acting or attempting to act as a substitute for another, or using or attempting to use a substitute, in any academic evaluation or assignment.

- Receiving external assistance during an examination or any academic exercise for credit unless expressly permitted by the instructor.

- Providing or receiving aid not permitted by the instructor in connection with any academic assignment;

- Communication in any manner with another student not permitted by the instructor during an examination;

- Working with others on graded coursework, including in-class, online, and take-home examinations, unless expressly permitted by the instructor;

- Unauthorized use or possession of camera telephones, text messages, computer disks, audio recorders, calculators, solution materials, photocopies, materials from previous classes, commercial research services, notes or other means to copy or photograph materials used or intended for academic evaluation not authorized by the instructor for use during the academic evaluation or assignment; or

- Possessing, reading, buying, selling or using any materials intended for an academic evaluation or assignment in advance of its administration without the knowledge and consent of the instructor.

- Facilitating, permitting or tolerating any of the above-listed items.

\footnotetext{
* Excerpted from the UNLV Office of Student Conduct- Student Academic Misconduct Policy. Available from: http://studentlife.unlv.edu/judicial/misconduct Policy.html
}

senting our expectations at the beginning of their CLS education that we can alleviate future unpleasant situations.

Although we have only used this segment during orientation for one group of 17 graduates (May 2010) with another group of students to be finished next year, exit surveys from the recent graduates indicate that cheating had never been discussed with most of them prior to entering the CLS Program. They were not well informed concerning definitions of cheating and the many examples that would be considered cheating. Many expressed that what we call cheating, e.g. assisting a friend during take home or online work, was common place and seemed acceptable in other courses both in high school and in prior university courses. At the onset some still did not believe it was really cheating but agreed to follow our policies. After the orientation session and through the use of course objectives most, but not all, realized the need for such academic integrity, what it means for learning and more importantly for personal integrity. To our knowledge we did not have any more of the issues with the online quizzes and exams. Below are some of the open responses students wrote in the exit surveys about the academic integrity and dishonest portion of the orientation session:

Student 1: Boy was I off base I mean I guess I just never thought about all the fallout from helping someone with their work. In something like CLS and medicine if they cannot do their own work then they can hurt someone.

Student 2: In other classes we worked together all the time. Now I realize that was probably not always a good thing to do but no one told us not and no one seemed to check. The teachers did not seem to care and we were all just trying to pass. Now that we have been through the CLS program I realize that there is a difference between helping someone, studying together, and cheating. 


\section{CLINICAL PRACTICE}

Student 3: I had not really thought about all of this before. I felt I was a person who did not cheat and I was a bit angry that this was part of our orientation - like we were little kids. But then as we went through the classes and different situations came up I thought about things differently I think we all did. I realized that there were times before when I crossed the line - but now I stopped myself. I think this was something I needed (we all needed) at the beginning of college.

Student 4: I wasn't a person who would cheat but I do think I've bent the rules before. I mean you have to sometimes to get by.

\section{ENHANCEMENTS TO ONLINE QUIZ/TEST FORMATS}

After lengthy discussions with the OIT department, several selective formatting changes were implemented in our quiz/exam structures to discourage cheating (Table 2). These included shortening the time allowed based on the number and type of questions involved. We also developed question alternatives so that Web Campus would randomly select one of two or one of three questions for a topic. This provided each student with a slightly different but equivalent quiz. We also set the quiz format to reveal one question at a time and did not release the scores until after all students had completed the quiz. Questions were also administered by Web Campus in random order for each student and multiple choice items were scrambled each time the question was given. Additional strategies that may minimize the opportunity for cheating include developing more short answer test questions which require open-ended responses and having students take quizzes at specific locations with a proctor. Web Campus has a prevision to allow a proctor with password access which allowed our students who were in their clinical rotations to take their weekly quizzes and the clinical final exam under supervision (Table 3).

For some course management systems there are programming codes that prevent printing (print, print screen, right click print and highlight copy \& paste). These software patch codes must usually be obtained through the course management system manufacturer or provided by the campus Information Technology center. We opted to use the code for online quizzes and exams but let students openly copy, download or print practice questions and other course materials.

Table 2. Changes to Online Test Format to Minimize Cheating Opportunities

1. Shorten quiz time to minimal based on number of questions Prevents rummaging through notes or textbook for answers

2. Develop question alternatives derived from same objective $A$ and $B$ versions of question.

Each student gets different but equivalent version of quiz/test

3. Allow Web Campus/Black Board to randomly select question alternatives

4. Randomize questions and order of answers within each question

5. Use multiple correct answers - select all that apply - not pre-set combinations

6. Reveal only one question at a time

7. Do not allow look-back at previous questions

8. Do not release scores or answers until after quiz time has closed

\section{SUMMARY}

Studies have shown that universities with pre-emptive policies are seeing some improvement in misconduct rates as well as more involvement from faculty. ${ }^{1,4,5,6}$ Both students and faculty are responsible for developing and maintaining academic integrity in the university setting. It is important to also define the responsibilities of students that observe an infraction by their peers as well as the role of instructional faculty. A cohesive plan with clear definitions and procedures, rights and responsibilities will help both faculty and students build a culture of academic integrity. Discussing these policies in advance will let both students and faculty share in the integrity of their education.

As educators delve more into the world of blended or fully online courses we must also concern ourselves with a variety of issues which arise in these non-traditional classroom settings. Because this newer generation of students was raised in an Internet-focused world they have very different concepts about how online materials can and should be used and where the boundaries of 


\section{CLINICAL PRACTICE}

Table 3. Security Options for Online Assessments

\begin{tabular}{|c|c|}
\hline Assessment Delivery Properties & Comments/Recommendations \\
\hline Dates Available & Limit Dates based on syllabus \\
\hline Deliver questions all at once/one at a time & Your choice - we usually deliver all at once \\
\hline Allow question titles to be seen or not & No - Titles can give away question purpose are for us to sort questions \\
\hline Allow questions to be revisited or not & Your choice - we usually allow them to go back and change answers if needed \\
\hline Question order & Random - different for each student \\
\hline Answer order & Random or scrambled \\
\hline Question alternatives & Use at least one alternative question for each. Let Web Campus randomly select. \\
\hline \multicolumn{2}{|l|}{ How to Display Assessment } \\
\hline $\begin{array}{l}\text { Display in same window or new browser } \\
\text { window }\end{array}$ & Your choice \\
\hline Set time limits for assessment & Time limits based on number and type of questions used \\
\hline Allow submission after time expires & We allow this in the beginning of the \\
\hline or not & semester for students to get familiar with this - then do not allow later \\
\hline \multicolumn{2}{|l|}{ Releasing Students' Scores } \\
\hline $\begin{array}{l}\text { Release after all assessments are } \\
\text { submitted }\end{array}$ & Select one of these options \\
\hline $\begin{array}{l}\text { Release after all assessments are } \\
\text { taken \& graded }\end{array}$ & As above \\
\hline $\begin{array}{l}\text { Release after assessment availability } \\
\text { time period is over }\end{array}$ & As above \\
\hline $\begin{array}{l}\text { Release after availability time period is } \\
\text { over and assessment is graded }\end{array}$ & As above \\
\hline $\begin{array}{l}\text { Release assessment statistics so students } \\
\text { can see the class performance }\end{array}$ & Yes on exams but not for quizzes \\
\hline \multicolumn{2}{|l|}{ Displaying Student Results } \\
\hline Show entire question text & Yes \\
\hline Show student's response & Yes \\
\hline Show correct answer & We never display answers. Students are directed to look things up \\
\hline Show student's score & Yes - tells them right/wrong \\
\hline Show feedback for each question & Usually the question objective \\
\hline Show grader's comments & Yes \\
\hline \multicolumn{2}{|l|}{ Security } \\
\hline $\begin{array}{l}\text { Restricted IP* addresses where students } \\
\text { can access assessment }\end{array}$ & For students at remote clinical sites \\
\hline IP address mask & As above \\
\hline Proctor password & As above \\
\hline
\end{tabular}

${ }^{*} \mathrm{IP}=$ Internet Protocol address

academic integrity might be. It is crucial for faculty to make sure everyone is on the same page: to provide students with the definitions of academic integrity and the boundaries of the use of online materials through written policies. It is also essential that faculty themselves model academic integrity by designing their courses with embedded safeguards, discussing expectations and policies with students, and enforcing policies regarding cheating when necessary.

\section{REFERENCES}

1. Jarc R, Fox V. There's a Hole in Our Moral Ozone and It's Getting Bigger: Survey of 29,000 high school students reveals entrenched habits of dishonesty. Report Card on the Ethics of American Youth (C) 2008 Josephson Institute. Available from: www.charactercounts.org . Accessed January 2009.

2. Grijalva TC, Nowell C, Kerkvliet J. Academic Honesty and Online Courses. Coll Stud J. 2008. 40:180-5

3. Bisping TO., Patron H, and Roskelley K. Modeling Academic Dishonesty: The Role of Student Perceptions and Misconduct Type. J Econ Edu. 2008. 39:4-21.

4. Schelling LP, Gilbert K, Spencer KJ, Pinks HS, Silva, RA. Multidimensional Scaling of College Students' Perceptions of Academic Dishonesty. J Higher Educ. 2008. 79:587-607. 


\section{CLINICAL PRACTICE}

5. McCabe DL. It Takes a Village: Academic Dishonesty and Educational Opportunity. Liberal Education. 2005. Summer/Fall: 26-31.

6. Harmon OR, Lambrinos J. Are Online Exams an Invitation to Cheat? J Econ Educ 2008. 39:116-25.

7. Stuber-McEwen D, Wiseley P, Hoggatt S. Point, Click, and Cheat: Frequency and Type of Academic Dishonesty in the Virtual Classroom. Online Journal of Distance Learning
Administration [serial online]. September 1, 2009; 12(3) Available from: ERIC, Ipswich, MA.

8. Josephson Institute of Ethics. A Study of Values and Behavior Concerning Integrity: The Impact of Age, Cynicism and High School Character. 2009 Report. Available from: http:// Josephsoninstitute.org/surveys/index.html Accessed March 2010.

The peer-reviewed Clinical Practice Section seeks to publish case studies, reports, and articles that are immediately useful, are of a practical nature, or contain information that could lead to improvement in the quality of the clinical laboratory's contribution to patient care, including brief reviews of books, computer programs, audiovisual materials, or other materials of interest to readers. Direct all inquiries to Libby Spence, PhD, CLS(NCA), Clin Lab Sci Clinical Practice Editor, University of Mississippi Medical Center, 2500 North State Street, Jackson, MS 39216, lspence@umc.edu.

Clinical Laboratory Science encourages readers to respond with thoughts, questions, or comments regarding these articles. Email responses towestminsterpublishers@comcast.net. In the subject line, please type the journal issue and lead author such as "CLIN LAB SCI 23(4) RE CONWAY-KLAASSEN". Selected responses may appear in the Dialogue and Discussion section in a future issue. Responses may be edited for length and clarity. We look forward to hearing from you. 